
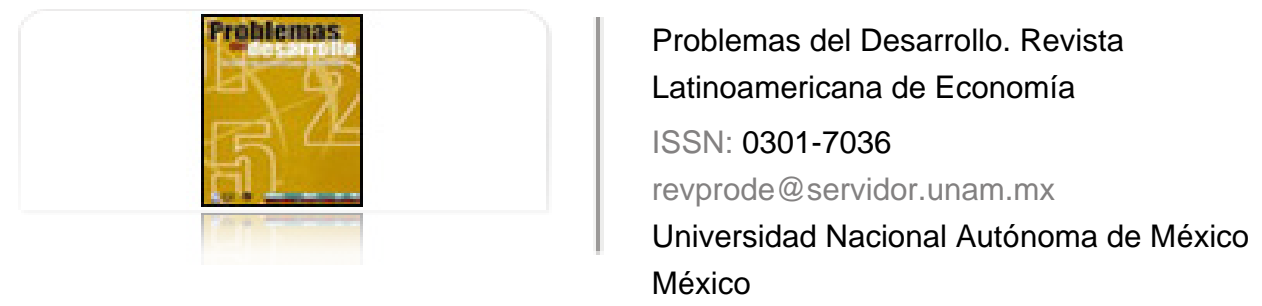

Silva Júnior, Luiz Honorato da; Sampaio, Yony

Notas Sobre Pobreza e Educação no Brasil

Problemas del Desarrollo. Revista Latinoamericana de Economía, vol. 41, núm. 163, octubre-

diciembre, 2010, pp. 75-97

Universidad Nacional Autónoma de México

Distrito Federal, México

Disponível em: http://www.redalyc.org/articulo.oa?id=11819762005

- Como citar este artigo

Número completo

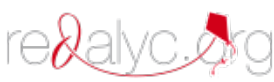

Mais artigos

- Home da revista no Redalyc

Sistema de Informação Científica

Rede de Revistas Científicas da América Latina, Caribe , Espanha e Portugal Projeto acadêmico sem fins lucrativos desenvolvido no âmbito da iniciativa Acesso Aberto 
Revista Problemas del Desarrollo, 163 (41), octubre-diciembre 2010

\title{
Notas Sobre Pobreza E EduCaÇÃo No Brasil
}

\author{
Luiz Honorato da Silva Júnior* e Yony Sampaio**
}

Fecha de recepción: 8 de junio de 2010. Fecha de aceptación: 12 de agosto de 2010.

RESUMO

Os baixos níveis de educação no Brasil estão associados à pobreza e à grande desigualdade social. Este trabalho parte dos determinantes educacionais para se destacar de que forma a pobreza reduz as oportunidades e tolhe a busca por maiores níveis educacionais. De modo sucinto é exposta a evolução da pobreza, das desigualdades e dos níveis educacionais. Constata-se redução da pobreza mas com marcantes desigualdades regionais. Em relação à educação há grande desnível entre escolas privadas e públicas, agravando as disparidades e reforçando os desníveis de renda. Foi atingida universalidade no ensino fundamental mas com qualidade muito baixa. Políticas recentes tem se voltado para esta questão, mas há necessidade de reforçar as condicionalidades e estimular a demanda por educação. Desse complexo quadro resulta a necessidade da açáo pública tanto no estímulo a uma maior demanda por educaçáo como na oferta de um ensino público de qualidade.

\section{PALAVRAS CHAVES}

Educação, pobreza, desigualdade de rendimento.

Profesor Adjunto del Campus de Agreste de la Universidad Federal de Pernanbuco, Brasil, correo electrónico: lula_honorato@hotmail.com

** Profesor titular del Departamento de Economía de la Universidad Federal de Pernanbuco, Brasil, correo electrónico: ysampaio@yahoo.com.br 
Luiz Honorato da Silva Júnior e Yony Sampaio

\begin{abstract}
Summary
The low levels of education in Brazil are associated with poverty and social inequality. The present paper based on the educational determinants emphasizes the way in which poverty reduces opportunities and makes it difficult to obtain higher education levels. It briefly traces the development of poverty, inequality and educational levels. We see that poverty exists, but with sharp regional differences. Within education there exist great disparities between the private and public schools, exacerbating the inequalities and the widening of income disparities. Basic universal education has been achieved, but with a very low quality. The latest policy has centered on this question, but it is necessary to strengthen the conditions and stimulate the demand for education. This complex framework shows the need for public action, both in promoting a greater demand for education and the provision of quality education in the public sector.
\end{abstract}

Key words: education, poverty, income inequality.

\title{
Résumé
}

Les faibles niveaux d'éducation au Brésil sont liés à la pauvreté et à l'inégalité sociale. Ce travail se base sur les facteurs déterminants de l'éducation pour mettre en relief de quelle manière la pauvreté réduit les chances et rend difficile la recherche de niveaux d'éducation plus élevés. Il y est exposé succinctement l'évolution de la pauvreté, de l'inégalité et des niveaux d'éducation. On s'aperçoit qu'il y a pauvreté, mais avec des différences marquées selon les régions. En matière d'éducation, il existe une grande disparité entre les écoles privées et publiques, ce qui exacerbe les inégalités et accroît les disparités entre les revenus. L'éducation élémentaire universelle a été atteinte, mais elle de très basse qualité. La politique récente s'est centrée sur cette question, mais il est nécessaire de renforcer les conditions et de stimuler la demande en éducation. De ce cadre complexe découle le besoin d'une action publique, pour fomenter une demande majeure d'éducation autant que l'impartition d'une éducation publique de qualité.

Mots clés : éducation, pauvreté, inégalité de revenus.

\section{Resumen}

Los bajos niveles de educación en Brasil están asociados con la pobreza y la desigualdad social. Este trabajo parte de los determinantes educativos para poner de relieve de que manera la pobreza reduce las oportunidades y dificulta la búsqueda de mayores niveles de educación. Sucintamente se expone la evolución de la pobreza, la desigualdad y los niveles educativos. Se percebe que hay pobreza, pero con marcadas diferencias regionales. En materia de educación existe una gran disparidad entre las escuelas privadas y públicas, exacerbando las desigualdades y el aumento de las disparidades en los ingresos. Se logró la educación básica universal, pero con una calidad muy baja. La política reciente se ha centrado en esta cuestión, pero hay necesidad de reforzar las condicionalidades y estimular la demanda para la educación. De este complejo marco resulta la necesidad de una acción pública, tanto en el fomento de una mayor demanda por educación como la prestación de una educación pública de calidad.

Palabras clave: educación, pobreza, desigualdad de ingresos.

\section{关于巴西的贫困与教育}

综述

巴西较低的教育水平与社会不平等有直接的关系。该文章从一些教育参数入手分析 贫困是如何限制了接受教育的机会和决定接受教育的层次。简洁地描述了贫困，不 平等和教育水平的演变。贫困有明显的地区差异。在教育方面公立和私立学校的很 大的差距，加剧了不平等和收入的差距。实现了普及基础教育，但其质量非常低。

最近的政策都集中在这个问题之上, 但有需要加强条件, 并促进对教育的需求。在 这种复杂的背景下，无论是在促进教育质量的提高或者在提供公共教育的需求上都 表明了采取公共行动的迫切需要。

关键词：教育，贫困，收入不平等。 
Notas Sobre Pobreza e Educação no Brasil

\section{INTRODUÇÁO}

O Brasil é o país do futuro. Este discurso positivista tomou força e se tornou popular no período do chamado milagre econômico, nutrindo de esperanças geraçóes de brasileiros que esperaram o futuro chegar. Mas quando este futuro chegará? Este provável "atraso" parece estar relacionado com alguns gargalos importantes que impedem o país de alcançar padróes de desenvolvimento verificados nos países desenvolvidos. Um desses, e talvez o mais importante, é o baixo e precário nível de escolaridade de seu povo, mesmo quando comparado com sociedades que possuem padróes de renda e desenvolvimento semelhantes a ele. ${ }^{1}$ Tal déficit educacional traz sérias conseqüências sócio-econômicas ao país, dentre elas, a manutenção dos elevados níveis de pobreza e a desigualdade de rendimentos verificada ao longo da história.

Recentemente, a pobreza e a desigualdade têm sido diminuídas ${ }^{2}$, e tal fato se dá, principalmente, em função das políticas sociais que tem transferido diretamente renda aos mais pobres. Mas o país não poderá (ou não deveria) manter tais políticas indefinidamente. E não se sabe ainda, se as políticas de transferência direta deixarão efeitos permanentes.

Neste sentido, discute-se muito acerca de políticas estruturadoras que minorem os problemas associados à pobreza, bem como em instrumentos de políticas para que não se perpetuem os programas de cunho assistencialistas, sempre muito úteis no aprisionamento político do cidadão. A esse respeito, existe consenso em toda a sociedade acerca da importância do papel que a educação desempenharia no processo de reduçáo permanente da pobreza.

Além de eficaz contra a pobreza, as vantagens de uma sociedade mais educada parecem incontestes (Lange y Topel, 2006). A educação traz inúmeros benefícios sociais: um indivíduo melhor educado tem maior produtividade, maior noção de cidadania, além de possuir maior portfolio para decidir sobre nutrição, saúde e planejamento familiar (Gurgand, 2005).

Vários estudos têm apontado para a importância da melhoria da qualidade da educação brasileira e a elevação de seus níveis, como etapa para resolução dos diversos problemas sócio-econômicos que o Brasil enfrenta, inclusive, no que tange à atenuação da pobreza (Ferreira y Veloso, 2006 y Barros, Mendonça y Henriques, 2001). Entretanto, o sistema educacional brasileiro parece se encontrar imergido no seio desses mesmos problemas. Assim, a educação deixa de ser uma panacéia para ser objeto de estudos.

O objetivo deste trabalho é contribuir com reflexôes sobre a relação entre pobreza e educação e fazer, de maneira sucinta, uma apresentação do status atual do sistema educacional brasileiro, assim como, das características de pobreza e da distribuição de renda

Conforme se pode ver em Silva Júnior (2009) e World Bank (2005)

Conforme Barros et al (1997 e 2003), Ferreira (2006), Rocha (2005) e Silva Júnior (2006) 
Luiz Honorato da Silva Júnior e Yony Sampaio

do Brasil. O trabalho começa tratando dos determinantes da busca por educação, destacando aspectos relacionados à pobreza, para em seguida tratar do problema da pobreza e da desigualdade no Brasil e como esta afeta o país. Em seguida, trata-se da educaçáo no Brasil, sendo feita rápida retrospectiva histórica de sua trajetória, e apresenta políticas recentes e características contemporâneas do sistema de educaçáo.

\section{DETERMINANTES EDUCACIONAIS}

Se a educação tem um papel importante na mobilidade social (Ferreira e Veloso, 2006) e aparece como um elemento crucial para resolver o problema da pobreza no Brasil, acredita-se que por outro lado, o problema da pobreza poderia afetar a continuidade na formaçáo escolar de alguns (Checchi, 2007). Isto tem ocorrido no Brasil? A pobreza tem afetado as decisôes individuais acerca do plano ótimo de escolarização da população brasileira? Caso afetem, tal fato parece apontar para uma grande armadilha lógica: o país tem muitos pobres porque apresenta diminuto nível educacional de sua população ou possui baixo nível de educação formal porque tem muitos pobres. Observe-se que essa armadilha aprisionara apenas os mais pobres e contribui intergeracionalmente para a manutençáo de elevados níveis de desigualdade.

Observe-se que para o indivíduo adquirir educação, existem duas condiçóes necessárias mínimas a serem satisfeitas: este indivíduo precisa demandar educação e, existe a necessidade da oferta desse serviço. Com relação à demanda individual, da mesma forma como ocorre na decisão de escolha de consumo de um bem ou serviço, ou na decisão de investimento de uma firma, alguns elementos influenciam a escolha ótima desse indivíduo. Pelo menos cinco fatores parecem decisivos: a renda familiar, as habilidades, o ambiente familiar do indivíduo, a qualidade da escola que ele pretende freqüentar e o retorno esperado da educação.

A renda familiar parece importante apenas quando ela é insuficiente para a manutenção das condiçôes de sobrevivência da família e as crianças e adolescentes em idade escolar são pressionados a contribuírem para a sua elevação, seja diretamente no mercado de trabalho ou indiretamente no suporte dos afazeres domésticos enquanto os membros mais velhos da família lutam pela sobrevivência. Neste sentido, a pobreza poderia influenciar a decisão de alguns pais em retirar muito precocemente suas crianças e adolescentes da escola.

As habilidades dizem respeito às capacidades que o indivíduo traz consigo e se distribuem de maneira heterogênea entre os indivíduos. Alguns indivíduos apresentam maior velocidade de aprendizagem, e tais habilidades, colaboram para a sua continuidade por mais tempo na escola. Aliás, esta deveria ser a principal característica determinante dos resultados educacionais de um indivíduo: sendo ele mais habilidoso deveria seguir com seus estudos até onde maximizasse seu retorno, sem que o baixo rendimento familiar o impedisse. 
Verifica-se que as habilidades estão altamente relacionadas com o ambiente familiar, ou se preferir, com o background familiar, ou ainda, como é frequentemente analisado, com a formação educacional dos pais. Indivíduos cujos pais estudaram mais tenderão a estudar mais. E existem pelo menos três prováveis motivos para que isto ocorra: primeiro, devido aos elevados retornos existentes à educação no Brasil, filhos cujos pais têm maiores resultados educacionais tendem a possuir maior renda e isto parece importante na decisão ótima de escolarização. Depois, parece haver transmissão intergeracional de talentos (Checchi, 2007) e, por último, maior background familiar cria um ambiente familiar propício para o estudo.

A qualidade da escola pode desempenhar um importante papel no quadro educacional de uma sociedade (Lee y Barro, 2001). Em um país onde as escolas públicas não possuem boa qualidade e não conseguem competir minimamente com as escolas privadas - estas freqüentadas somente pelos grupos sociais mais abastados -, tais características podem produzir um quadro de severa desigualdade de renda, elevando as desigualdades de rendimentos desse país e diminuindo a mobilidade social.

Os retornos à educaçấo servem como combustível no processo. Os indivíduos não estudam somente porque almejam ser melhores cidadãos, possuidores de senso aguçado e crítico da realidade, mas o fazem também, porque almejam ter proveito de seus investimentos pessoais.

Logicamente que maiores perspectivas de retorno elevam a disposição ao estudo. Por outro lado, quanto maior o nível de escolaridade de uma sociedade, menores serão as expectativas de retorno à educação. Os retornos á educação não são independentes dos outros fatores: a qualidade da escola amplia as perspectivas futuras, o background familiar propicia melhor entendimento das oportunidades e futuros retornos e, por fim, a renda familiar condiciona as possibilidades de maior e melhor dedicaçáo ao estudo.

Observe que, por um lado, as habilidades e background familiar estão fora do conjunto de escolha dos indivíduos, afinal ninguém escolhe sua família antes de nascer. E se os indivíduos mais pobres tendem a possuir menores dotaçóes de habilidades e background familiar. Tal cenário poderia manter um quadro de persistência intergeracional da pobreza com baixa mobilidade social. Por outro lado, a decisão sobre a oferta de ensino e sobre a qualidade da escola é uma decisão social que passa pela escolha de alocação de recursos.

Portanto, a depender da maneira como estes dois importantes fatores interagem na produçáo de conhecimento, políticas de alocaçóes eficientes poderiam ser importantes para o país (Brunello e Checchi, 2005). Então, a questâo que se levanta seria: como interagem o background familiar e a qualidade da escola no Brasil? Se estes fatores se apresentassem como substitutos técnicos, eventual escassez de background familiar poderia ser substituída por uma escola de melhor qualidade, e tal solução poderia acabar com eventuais armadilhas e aumentar a mobilidade social via educação. 
Luiz Honorato da Silva Júnior e Yony Sampaio

\section{POBREZA, DESIGUALDADES E EDUCAÇÃO NO BRASIL}

O Brasil não pode ser visto como um país pobre e sim com muitos pobres. Comparativamente aos outros países do mundo, o Brasil se classifica como um país de renda per capita média, onde o montante de recursos disponíveis seria suficiente para garantir o mínimo essencial a todos, de modo que a persistência da pobreza absoluta se deve à má distribuição da renda. Essa é a conclusão de Barros et al (2001) e Rocha (2005).

Segundo Arbache (2003), em fins de 1960 e início de 1970 o Brasil experimentou taxas de crescimento absolutamente elevadas, no período do chamado "Milagre Econômico", e além do elevado crescimento econômico que, em alguns anos foi além dos $10 \%$, verificou-se diminuição significativa da pobreza, e um processo de concentração de renda associado ao elevadíssimo crescimento dos retornos à educação e aumento dos retornos de capital.

Observou-se também que nos últimos trinta anos no país, ocorreram algumas mudanças importantes que dizem respeito à pobreza, destacando-se que houve uma significativa diminuição da pobreza nos períodos posteriores aos planos econômicos de 1986 e 2004. No caso do Plano Cruzado houve um recrudescimento da inflação após o seu insucesso, com conseqüente elevação da pobreza. Já o Plano Real parece ter conseguido melhores resultados tanto em seu objetivo principal, que era o de controle da inflação, assim como, em um objetivo secundário: a redução da pobreza (Baer, 2002).

Outra característica marcante dos últimos trinta anos foi a redução da pobreza no período, e isso vem se dando em todas as regióes do país. A figura 1 apresenta a evolução histórica da proporção de pobres nas cinco regióes do Brasil. Os resultados foram obtidos a partir do percentual de pessoas abaixo de uma linha de pobreza arbitrada com renda domiciliar per capita inferior a $\mathrm{R} \$ 75,50$, equivalentes a $1 / 2$ salário mínimo vigente em agosto de 2000. Na opinião de Rocha (2005), a pobreza se reduziu lentamente no país nos últimos trinta anos, sempre foi muito susceptível a planos econômicos e programas de transferências diretas de renda. Parece haver uma necessidade preemente de políticas mais efetivas neste sentido.

Alternativamente, Rocha (2005) apresenta a tabela 1 mostrando que apesar das importantes transformaçóes estruturais que o país passou nos últimos trinta anos, as regióes Norte e Nordeste continuam sendo negativamente destacados por sua trajetória de maior pobreza.

A referida tabela mostra ainda que a evoluçáo mais adversa ocorreu no Norte Urbano, onde se assistiu a triplicação, em dezoito anos, da sua participação no total de pobres do país. Contudo, o Nordeste tem resultados ainda mais preocupantes tanto pela intensidade do fenômeno quanto em relação ao contingente envolvido: cerca de 13 milhôes de pessoas, quase metade dos pobres brasileiros em 1999, apesar da melhora tanto absoluta quanto relativa.

Carneiro (2003) mostrou a distribuição dos pobres no Brasil por regiôes e áreas. O autor definiu como pobre alguém que vivia num domicílio com renda per capita menor 
Figura 1 - Evolução histórica da proporção de pobres nas cinco regiões do Brasil.

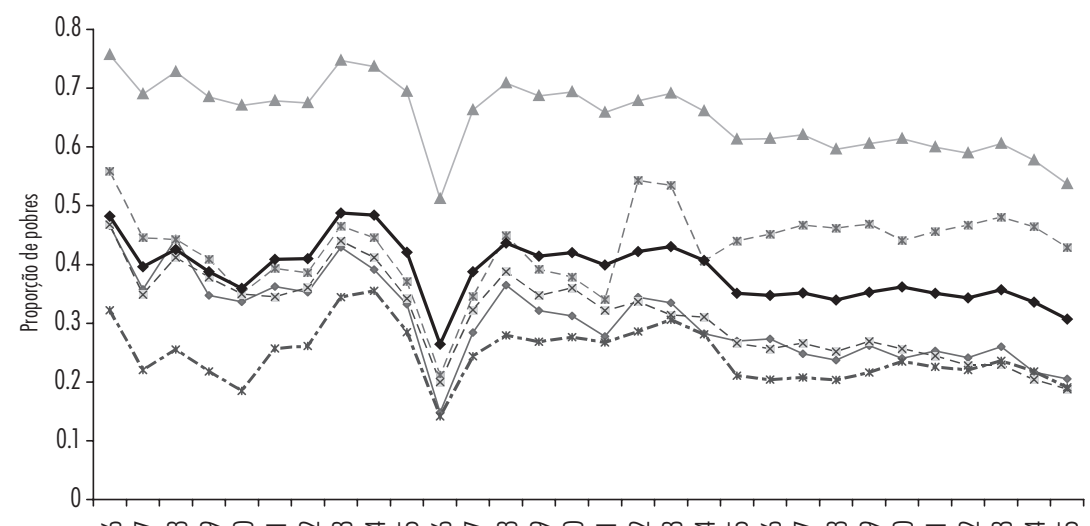

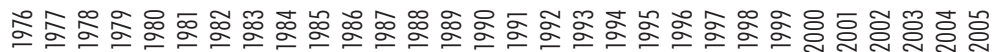
anos

$\rightarrow-$ Região Centro-oeste $\quad-*$ - Região Norte $\rightarrow$-Região Nordeste $-*-$ Região Sul $-*$ - Região Sudeste $\rightarrow$ Brasil

Fonte: Ipeadata, elaborado pelo autor.

Tabela 1 - Proporção e participação (\%) dos pobres por região 1981, 1990 e 1999.

\begin{tabular}{lcccccc}
\hline \multirow{2}{*}{ Localidade } & \multicolumn{2}{c}{1981} & \multicolumn{2}{c}{1990} & \multicolumn{2}{c}{1999} \\
\cline { 2 - 6 } & Proporção & Participac̦ão & Proporc̦ão & Participac̦ão & Proporc̦ão & Participac̦ão \\
\hline Brasil & 34,58 & 100 & 30,25 & 100 & 21,11 & 100 \\
Norte Urbano & 47,88 & 3,75 & 43,24 & 5,29 & 40,71 & 9,57 \\
Nordeste & 56,52 & 49,01 & 45,83 & 45,04 & 29,44 & 40,23 \\
Sudeste & 23,72 & 30,52 & 23,05 & 33,37 & 17,61 & 36,37 \\
Sul & 21,36 & 10,01 & 20,13 & 10,38 & 11,82 & 8,66 \\
Centro-Oeste & 35,09 & 6,71 & 24,94 & 5,92 & 15,36 & 5,17 \\
\hline
\end{tabular}

Fonte: Rocha (2005)

que o equivalente a R \$ 65,00 por mês (cerca de 35 dólares), considerando os preços da Área Metropolitanas de São Paulo, estabelecendo assim, diversas linhas de pobreza, tanto regionais como setoriais. A tabela revela uma forte concentração da pobreza no Norte Urbano e Nordeste, apesar da significativa reduçáo no tempo. A figura 2 apresenta a distribuição de pobres por região e área no Brasil, segundo o referido autor.

A figura revela que há uma forte concentração de pobres no Nordeste e essa concentração é especialmente mais contundente nas suas áreas rurais. No período entre 1993 a 
Luiz Honorato da Silva Júnior e Yony Sampaio

Figura 2 - Distribuição de Pobres por Região e Área no Brasil

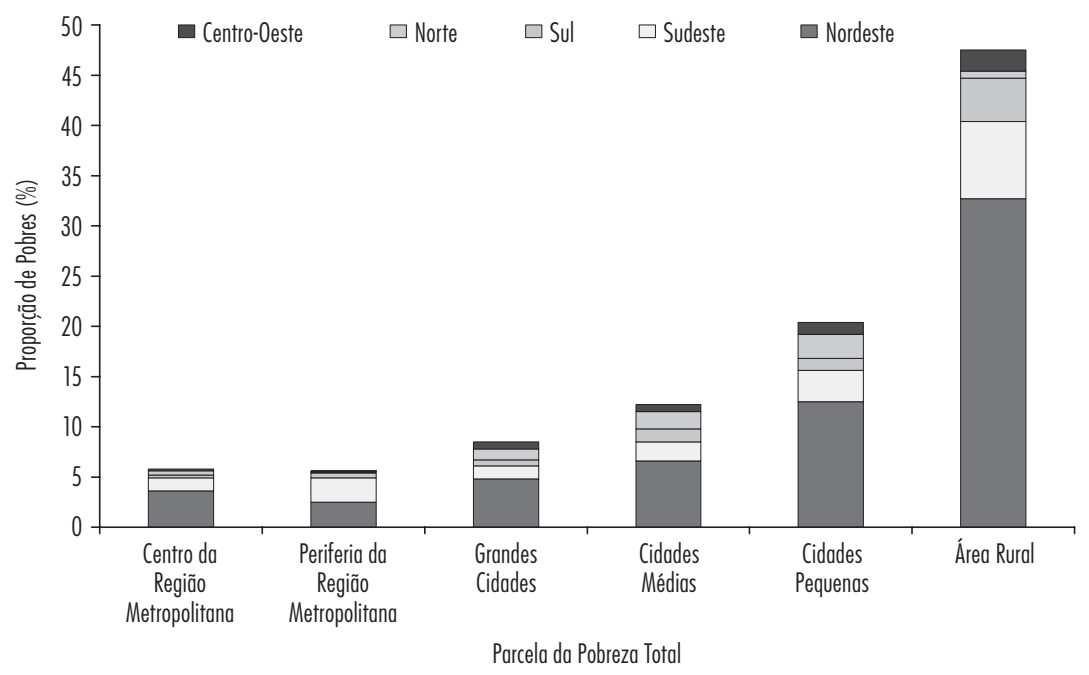

Fonte: Carneiro 2003, tabulação própria.

1998, a pobreza caiu menos no Nordeste nas áreas rurais e nas áreas urbanas de pequeno e médio porte. Conseqüentemente, a pobreza ficou mais concentrada nessas áreas. Este perfil representa um contraste radical à percepção comum da pobreza nas favelas das mega-cidades de São Paulo e Rio de Janeiro, onde a pobreza é mais visível. Na verdade, os pobres das áreas metropolitanas das grandes cidades do Sudeste constituem juntos 3,7\% dos pobres no Brasil ou 7\% dos pobres urbanos no Brasil. Cabe ressalvar, no entanto, que na área rural a renda monetária, analisada nestas pesquisas, representa apenas uma parcela da renda total, pois não inclui a renda não monetária e o auto-consumo, o que implica em uma super estimativa da pobreza.

Contrariamente às conclusôes apresentadas por Carneiro, Rocha (2005) afirma que a principal alteração espacial da pobreza nos últimos trinta anos no Brasil foi a redução da pobreza rural, à medida que o país se urbanizava, a pobreza tornava-se essencialmente urbana e metropolitana. Tal mudança propiciou que a pobreza se tornasse mais visível e associada à elevada desigualdade de renda, criando um ambiente favorável a fortes tensôes sociais e violência urbana. ${ }^{3}$

3 A aparente contradiçáo das análises feitas por Rocha (2005) e Carneiro (2003) no que diz respeito ao aumento ou redução da pobreza rural se dá pelo uso alternativo de "linhas de pobreza" diferentes pelos autores. 
Rocha (2005) desenhou um quadro comparativo entre a pobreza metropolitana das duas maiores cidades do Brasil, São Paulo e Rio de Janeiro, e a pobreza rural nordestina, pobreza típica de sociedades que se situam à margem do crescimento urbano-industrial. Comparando as duas realidades percebem-se diferenças que explicitam a heterogeneidade da pobreza no Brasil. A pobreza rural nordestina consiste de uma sub-população relativamente homogênea e numerosa, essas famílias são mais numerosas e os chefes de famílias são em sua maioria analfabetos. Em contrapartida, na pobreza metropolitana do Rio e de São Paulo, (contrariamente aos nordestinos, verifica-se que a maioria dos chefes de famílias trabalha como empregados (78\%) e cerca de metade deles com carteira assinada, nos setores de comércio e serviços. Além disso, o acesso à eletricidade e ao abastecimento de água é praticamente universal, apenas havendo déficits em relação ao esgotamento sanitário (29\%).

Em um país de proporçôes continentais é natural que a pobreza se apresente com características diversas, conforme suas regiōes. Diante de realidades tão distintas, quanto as que se verificam nas diversas áreas e regiôes brasileiras, a educação, com formas e ênfases diferenciadas, se apresenta como um importante elemento comum das políticas anti-pobreza.

As evidências permitem relacionar pobreza e baixo nível de escolaridade. Apesar de se saber que os indivíduos com baixo nível de escolaridade não estão necessariamente condenados à pobreza, entre os pobres, predominam indivíduos com baixo nível de escolaridade, conforme verificado por Barros, Machado y Mendonça (1997). Tal associação cria uma terrível armadilha social: quem é pobre tende a receber menos educação formal e quem recebe menos educação formal tende a ser mais pobre. criando uma difícil armadilha social.

Uma maneira interessante de ver tal associação consiste em plotar a escolaridade média e a proporção de pobres entre os municípios brasileiros. A figura 3 mostra esta relação para 5507 municípios a partir dos dados do último Censo, no ano de 2000. É impressionante a regularidade visual que contrasta a figura. Parece denunciar a dificuldade que os indivíduos residentes em municípios mais pobres têm em permanecer por mais tempo na escola. Outra constatação interessante é a de a quase totalidade dos municípios do interior do Nordeste se encontra na parte direita da figura, evidenciando como tal problemática é ainda mais importantes para a região mais pobre do Brasil, que possui os maiores índices de pobreza e as menores médias de escolarização entre os municípios brasileiros.

Não é de se estranhar tais resultados alarmantes para as regiōes Norte e, principalmente, Nordeste do Brasil. ${ }^{4}$ As razóes que levam estas regióes a apresentarem resultados tão ruins em relação ao restante do Brasil estão relacionadas a razões históricas e as origens da formação social. Desde o início, favorecida pelas condiçôes edafo-climáticas,

4 Os trabalhos de Rocha (2005) e Silva Júnior (2006) apresentam um quadro do status da pobreza. 
Luiz Honorato da Silva Júnior e Yony Sampaio

Figura 3 - Média de Escolarização e Proporção de Pobres de 5507 Municípios Brasileiros.

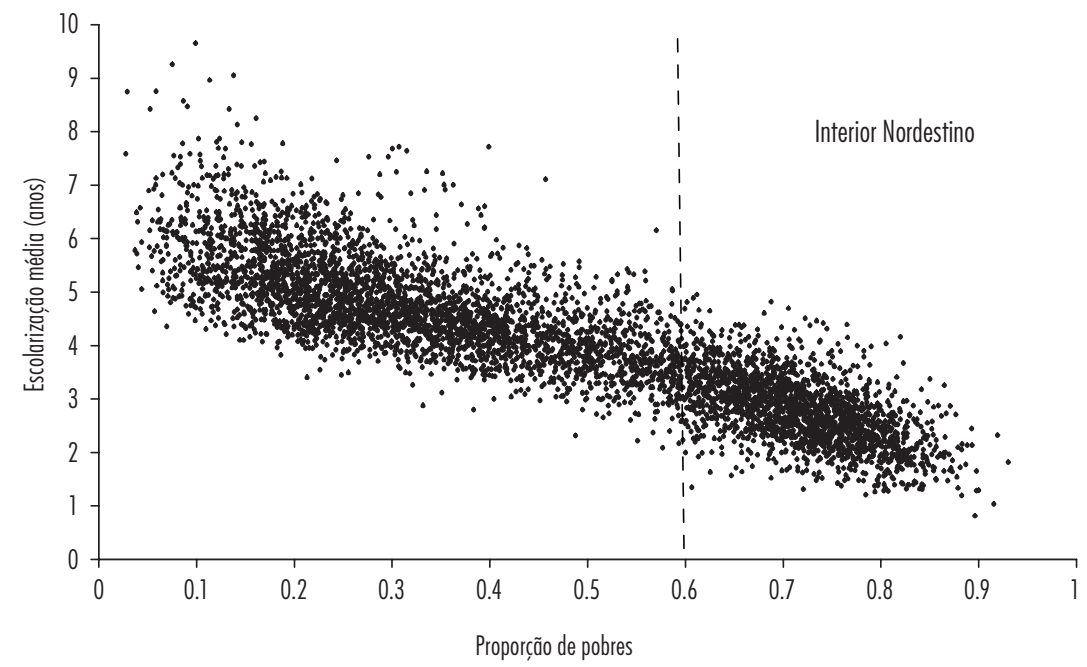

Fonte: Censo 2000 do IBGE, elaborado pelo autor.

a regiāo Nordeste do Brasil abrigou uma agricultura na forma de plantation da canade-açúcar, importando mão-de-obra africana para o trabalho. Enquanto que as outras regiốes do país tiveram a colonização mais tardia e acelerada depois da abolição da escravatura.

A regiáo Norte do Brasil recebeu apenas recentemente incentivos de ocupação. Praticamente coberta pela selva amazônica, sua ocupação demográfica se deu mais efetivamente apenas na década de sessenta e atraiu, sobretudo, nordestinos que fugiam das constantes secas. Por outro lado, as regióes mais ricas do Brasil, sobretudo São Paulo e Rio de Janeiro, atraíram mão-de-obra mais bem qualificada, e com apoio de políticas públicas, começaram, no início do século vinte, o processo de industrialização no Brasil.

Além das marcantes diferenças regionais no Brasil, é importante perceber que ainda existem grupos que apresentam uma maior vulnerabilidade em se situar na condição de pobreza. No que diz respeito a faixas etárias, observa-se maior vulnerabilidade para os indivíduos que se situam nas idades extremas: infância e velhice, em função de suas limitaçóes e debilidades.

A figura 4 retrata a proporção de pobres (\%) por faixas etárias no Brasil. Mais da metade das crianças entre zero e dez anos de idade é pobre, porque está inserida em uma 
família pobre. ${ }^{5}$ Esta constatação retrata o ciclo de vida das famílias onde no seu início combina a inserção dos pais no mercado de trabalho e o nascimento dos filhos. Para Rocha (2005) sob esta combinação, recomenda-se políticas anti-pobreza para famílias com crianças em tenra idade.

Figura 4 - Proporção de Pobres por Faixas Etárias no Brasil.

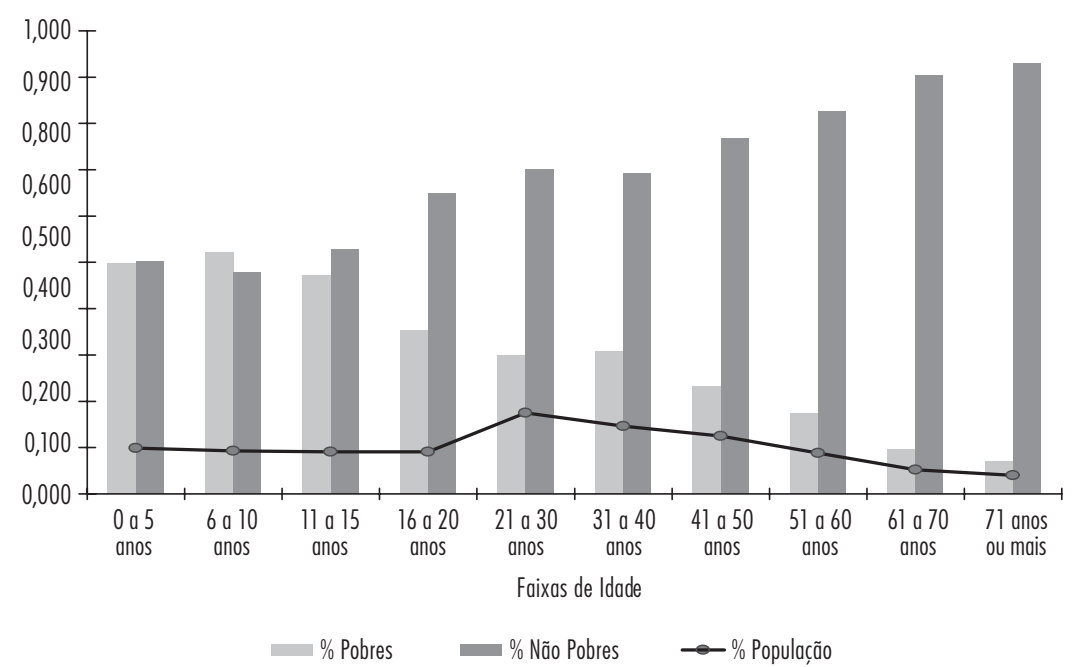

Fonte: PNAD 2007, elaboração própria.

O outro grupo vulnerável, os idosos, têm sido assistidos pela previdência social e por transferências de renda do sistema nacional de assistência social. Desde a Constituição de 1988 eles têm a garantia de receber benefícios no valor de um salário mínimo e, tais valores, tem sido determinantes para que a incidência de pobreza neste grupo seja comparativamente baixa.

Nos últimos anos, as políticas anti-pobreza têm ganhado maior apelo, principalmente aquelas baseadas em transferências de renda. A maioria dessas políticas consiste em transferências monetárias vinculadas a outras açôes sociais focadas em públicos específicos. Segundo Sabóia y Rocha (2002) a justificativa para tal política consiste no fato de que, em economias modernas e monetizadas, a cidadania plena somente poderá ser exercida por

5 O cálculo foi procedido utilizando os dados de pessoas da PNAD 2007, considerando pobres os indivíduos localizados abaixo de uma linha de pobreza de R \$ 190,00 para a renda familiar per capita. Este valor equivale a 1 122 salários mínimos em setembro de 2007. 
Luiz Honorato da Silva Júnior e Yony Sampaio

seus cidadãos se estes dispuserem de renda suficiente para o atendimento de suas necessidades. Ainda segundo os referidos autores, o bem estar do indivíduo é maior quando ele dispóe de renda, em comparação com recebimentos sob forma de bens e serviços públicos.

Uma indagação recorrente quando se discute este tema é o quantum que custaria eliminar a pobreza no Brasil. Ao se entender a pobreza apenas como insuficiência de renda, o custo de sua erradicaçáo é associado à eliminação do hiato de renda ${ }^{6}$, ou seja, ao montante de recursos necessários para elevar a renda dos pobres ao valor da linha de pobreza. A partir da $\mathrm{PNAD}^{7}$, observa-se que a estimativa desse valor em 2007 , assumindo uma única linha de pobreza equivalente a R \$190,00 (meio salário mínimo da época), para a renda per capita familiar, era de R \$ 59 bilhóes, ou o equivalente a 2,3\% do PIB daquele ano. ${ }^{8}$ Parece um valor modesto diante de seus benefícios, mas não se pode esquecer que para tal política encontrar êxito, necessitaria ser repetida ao longo de muitos anos, talvez décadas, até que aparecessem seus efeitos de maneira sustentável.

\section{4 - A EDUCAÇÃO NO BRASIL}

O sistema educacional público brasileiro possui as características próprias de países em desenvolvimento: baixo salário e despreparo de professores, pressão econômica de pais que necessitam do trabalho das crianças, evasão escolar antes do término do ensino fundamental, elevado número de jovens e adultos que não concluem a escolarização em idade regular, formação deficiente de parte dos profissionais da educação, grande número de alunos por sala, além de outros problemas de ordem estrutural, como falta de (boas) bibliotecas, e em alguns casos, até de energia elétrica e giz.

Se o sistema educacional público brasileiro possui características de países em desenvolvimento, por outro lado, o sistema educacional privado do Brasil revela uma outra realidade. Durante a avaliação feita pelo IDEB $^{9}$ no ano de 2007 as notas obtidas pelo sistema privado no ensino fundamental inicial, ensino fundamental final e ensino médio foram de 6; 5,8 e 5,6, respectivamente, contra 4; 3,5 e 3,2 do sistema público (IDEB, 2008). Da mesma forma, a classificação do Brasil no ranking do Programa Internacional de Avaliação de Alunos (PISA) ficaria próximo à de vários países europeus, se tivessem

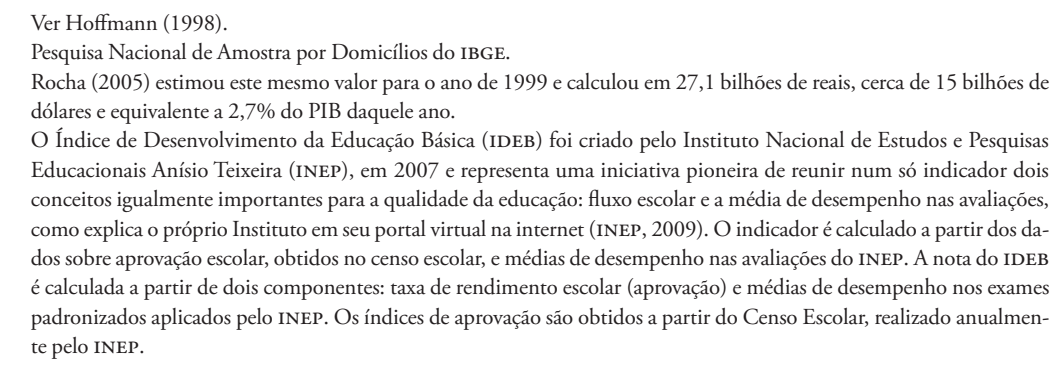

O Índice de Desenvolvimento da Educaçáo Básica (IDEB) foi criado pelo Instituto Nacional de Estudos e Pesquisas Educacionais Anísio Teixeira (INEP), em 2007 e representa uma iniciativa pioneira de reunir num só indicador dois conceitos igualmente importantes para a qualidade da educação: fluxo escolar e a média de desempenho nas avaliaçóes, como explica o próprio Instituto em seu portal virtual na internet (INEP, 2009). O indicador é calculado a partir dos dados sobre aprovaçáo escolar, obtidos no censo escolar, e médias de desempenho nas avaliaçóes do INEP. A nota do IDEB é calculada a partir de dois componentes: taxa de rendimento escolar (aprovaçáo) e médias de desempenho nos exames padronizados aplicados pelo INEP. Os índices de aprovaçáo sáo obtidos a partir do Censo Escolar, realizado anualmente pelo INEP. 
sido computados apenas testes aplicados nas escolas privadas brasileira (OCDE, 2008). O Brasil sairia da 49a para a $27^{a}$ colocação, empatando com a Hungria, um pouco abaixo da Noruega e à frente de Portugal, Itália, Espanha e Grécia. As diferenças assistidas entre os sistemas público e privado de educação no Brasil revelam duas realidades distintas e o perfil excludente que a educação pode gerar num país, contribuindo para a perpetuação das desigualdades e da pobreza.

\section{1 - Indicadores Educacionais}

A precariedade e a desigualdade do sistema educacional nos dias atuais parece ser o produto das concepçôes, açôes e políticas educacionais observadas na história do país. Como está a educação brasileira neste novo milênio? Segundo o relatório da OCDE (2008) o país continua com resultados muito ruins em comparaçóes internacionais. Para Ferreira e Veloso (2006) duas características distinguem o Brasil no contexto internacional: a elevada desigualdade de renda e a baixa escolaridade média da força de trabalho, mesmo em comparação a países em estágio de desenvolvimento semelhante.

Três consideraçôes importantes acerca da educação e suas relaçôes econômicas no Brasil podem ser feitas. A primeira é que a educação parece ser o mais importante fator explicativo da determinaçáo de salários e da desigualdade de renda no Brasil. De acordo com Arbache (2003), o acesso à educação é a mais promissora forma de se reduzir a desigualdade e a pobreza no Brasil. Entretanto, as respostas a essa política, pressupóem respostas de longo prazo.

A segunda é a de que parece que a redução da pobreza absoluta no Brasil passa por mudanças estruturais no sistema educacional que garantam o acesso à escola e à educação de boa qualidade para os mais pobres. No que tange as desigualdades de rendimentos no mercado de trabalho, segundo Amadeo et alii (1994), estas não são criadas apenas devido a mecanismos próprios desse mercado, tais como segmentação e discriminação, mas, principalmente, devido às diferenças educacionais entre os indivíduos.

Por fim, segundo Menezes-Filho (2001), o Brasil desde meados da década de 1990 tem conseguido aumentar de maneira significativa o acesso e a freqüência escolar. Entretanto, um dos problemas que ainda se evidencia com veemência, é o de como melhorar a qualidade da educação que é oferecida para os alunos na rede pública.

Verifica-se que uma política isolada como o aumento do tempo de educação compulsória, por exemplo, pode não trazer os resultados esperados. A tabela 2 mostra que nem mesmo o país sul americano que possuía a maior escolaridade média, não alcançava o seu tempo de educação compulsória. Outro aspecto interessante é que a escolaridade média dos países que têm educação compulsória de nove anos é maior que aqueles que possuem educação compulsória de dez anos. Portanto, obrigatoriedade, necessariamente, não aumenta a escolarização, caso não existam mecanismos de acompanhamento e de cobrança de responsabilidades. 
Luiz Honorato da Silva Júnior e Yony Sampaio

Tabela 2 - Características Econômicas e Educacionais de 11 Países Sul-Americanos.

\begin{tabular}{lccccc}
\hline $\begin{array}{l}\text { Países } \\
\text { Selecionados }\end{array}$ & $\begin{array}{c}P I B \\
\text { per Capita } \\
\left(P P C^{*}\right)\end{array}$ & $\begin{array}{c}\text { Índice } \\
\text { de Gini }\end{array}$ & $\begin{array}{c}\text { Gastos com } \\
\text { Educacáa } \\
\text { (\%PPB) }\end{array}$ & $\begin{array}{c}\text { Educacãa } \\
\text { Compulsória } \\
\text { (anos) }\end{array}$ & $\begin{array}{c}\text { Escolaridade } \\
\text { média } \\
\text { (anos) }\end{array}$ \\
\hline Argentina & $15.105,98$ & 0,5132 & 4,8 & 9 & 8,8 \\
Chile & $12.447,24$ & 0,5492 & 4,0 & 9 & 7,5 \\
Uruguai & $10.847,81$ & 0,4485 & 3,2 & 10 & 7,6 \\
Brasil & $8.710,04$ & 0,6450 & 4,2 & 8 & 4,9 \\
Colômbia & $8.436,31$ & 0,5862 & 5,2 & 8 & 5,3 \\
Venezuela & $7.158,91$ & 0,4820 & - & - & 6,6 \\
Peru & $6.507,47$ & 0,5202 & 3,0 & 11 & 7,6 \\
Guiana & $4.825,15$ & 0,4320 & 8,4 & 10 & 6,2 \\
Paraguai & $4.687,30$ & 0,5836 & 4,4 & 9 & 6,2 \\
Equador & $4.472,33$ & 0,5355 & 1,0 & 10 & 6,4 \\
Bolívia & $3.056,21$ & 0,6005 & 6,3 & 8 & 5,6 \\
\hline
\end{tabular}

Fonte: World Bank (2005), elaboraç̃õo do autor.

* Em Paridade do Poder de Compra

Quando se compara a escolaridade média brasileira com a de países de nível de desenvolvimento aproximados, verifica-se, claramente, a precariedade de seus resultados. Entre 11 países da América do Sul, o Brasil possuia no ano 2000, a menor média de escolaridade entre eles, apesar de possuir um dos maiores PIB per capita da regiáo. Por outro lado, o país apresenta a maior desigualdade entre os relacionados, valor muito superior aos vizinhos mais pobres. Apresenta também gastos com educação, como proporção do PIB, superior a diversos países com escolaridade média mais elevada, uma clara indicação de que não é apenas um problema de falta de recursos, mas de má utilização dos mesmos.

A figura 5 apresenta a escolaridade média e o índice de Gini para uma amostra de 87 países para o ano 2000. Note que a desigualdade de renda tende a ser menor em países onde a média de escolarização é maior. Nesta amostra, o Brasil é o país que possui a pior desigualdade de renda e uma das piores médias de escolarização.

Para Checchi (2007) este resultado advém do fato de que mais pessoas tendo acesso à educação terão melhores oportunidades de emprego, ou porque maior igualdade em escolarização aumenta a mobilidade social e, portanto, diminui a desigualdade de rendimentos. A figura destaca a participação de alguns países com alto, baixo e médio desenvolvimento.

Muitas são as políticas propostas para a melhoria da educação no Brasil. ${ }^{10}$ Elas passam sempre pelo prisma do aumento da parcela dos gastos públicos para a educação,

10 O trabalho de Ferreira e Veloso (2006) formula algumas propostas para uma nova política educacional. 
Figura 5 - Escolaridade Média da População Adulta e Coeficiente de Gini de 87 Países Selecionados.

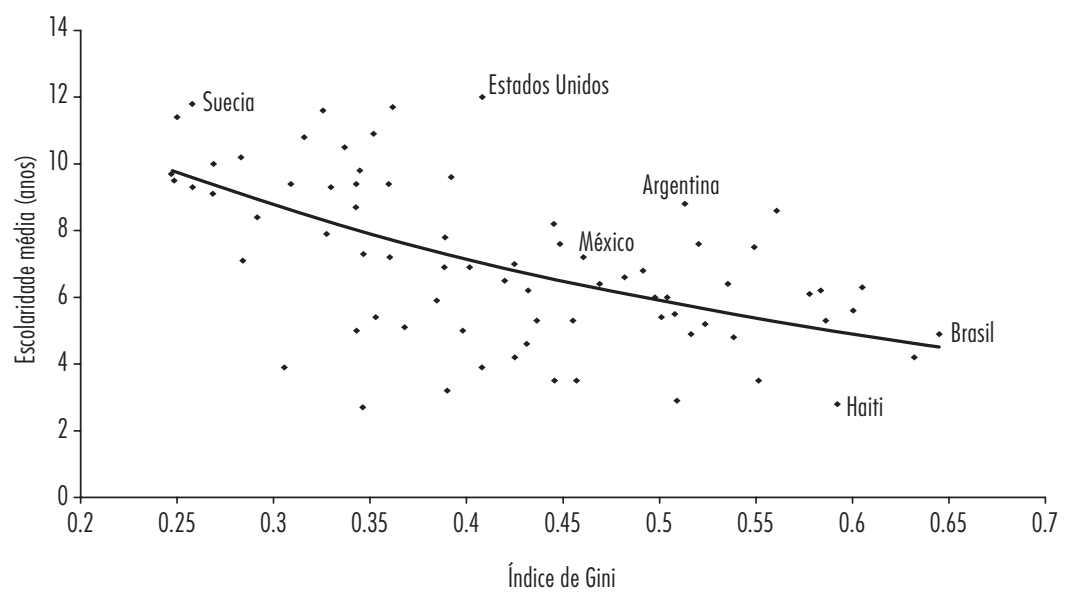

Fonte: World Bank (2005), elaboração do autor.

ainda que este argumento não esteja explícito. Entretanto, gastar mais, necessariamente, não significará melhores resultados, deve-se atentar para a eficiência alocativa desses gastos.

Entre as muitas políticas propostas para a melhoria da educação, Barros (1997) aponta para a necessidade da política educacional contar com um programa regional de melhoria das infra-estruturas de educação e da qualidade dos serviços oferecidos. Um passo fundamental para isso seria a mudança no perfil dos professores que são responsáveis pela educação, pois baixos salários levam a que, predominantemente, profissionais de baixa qualificação passem a se dedicar ao ensino. $\mathrm{O}$ autor ainda chama a atenção para a importância da educação básica, pois esta é cada vez mais crucial nos tempos atuais, tendo em vista a demanda por flexibilidade do trabalhador requerida pelas novas tecnologias. O pré-requisito para que um indivíduo tenha capacidade de migrar entre funçôes, sem grandes perdas de produtividade é exatamente uma boa educação básica.

Numa amostra para 77 países, a figura 6 mostra o desempenho desses países em função do percentual de seus gastos com relação aos seus PIBs. Países pobres como Lesoto e Quênia têm alocado uma significativa parcela de sua riqueza no setor educacional, entretanto a escolarização média não corresponde à monta de seus gastos. É claro que a figura apresenta apenas uma "fotografia no tempo" e, portanto, é possível que alguns desses países tenham mudado em períodos recentes suas políticas de gastos, mas é pouco provável que todos o tenham feito. 
Figura 6 - Período Médio de Escolarização de Adultos versus Gastos com Educação como Proporção do PIB de 77 Países Selecionados.

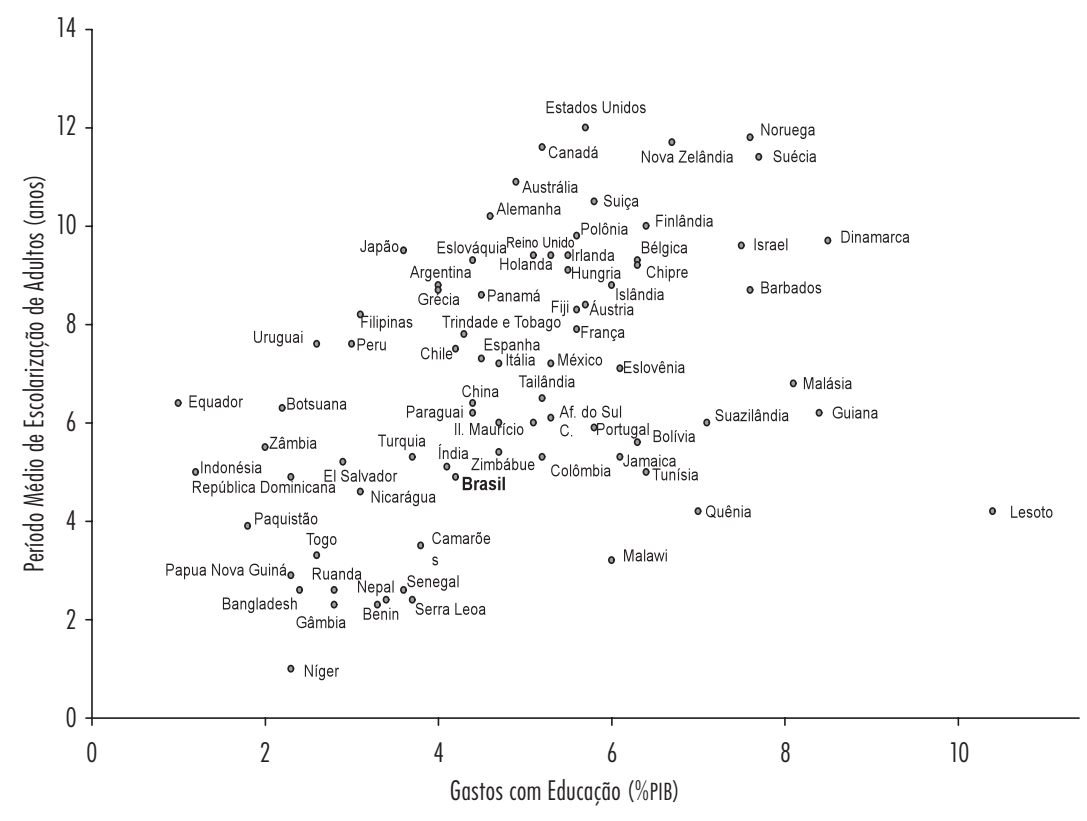

Fonte: World Bank (2005), elaboração do autor.

A figura 7 apresenta uma série histórica da escolarização média para as cinco regiôes do Brasil. Em 25 anos a média nacional cresceu 70\%, e no Nordeste dobrou. Fato é que a política educacional numa realidade complexa, como é a brasileira, não é algo fácil de construir, já que se trata de uma sociedade profundamente marcada por desigualdades.

Segundo Ferreira e Veloso (2006) a educação, ou a falta dela, afeta a desigualdade de renda no Brasil por dois motivos. Um deles é a elevada desigualdade educacional da força de trabalho. O outro é a alta taxa de retorno à educação no país. Segundo os referidos autores, se o Brasil tivesse não somente a mesma distribuição educacional, mas também a mesma estrutura de retornos à educação dos Estados Unidos, essa desigualdade se reduziria em 2/3.

Alguns trabalhos têm mostrado que o aumento da escolarização é a variável mais importante na determinaçáo do estado de pobreza de um indivíduo. Há ainda, uma ampla, crescente e recente literatura que mostra uma tendência de relação negativa entre desigualdade de renda e resultados educacionais, dentre elas os trabalhos de Atkinson (1999), 
Figura 7 - Série Histórica da Escolaridade Média para as Cinco Regiões do Brasil e para o Total do País.

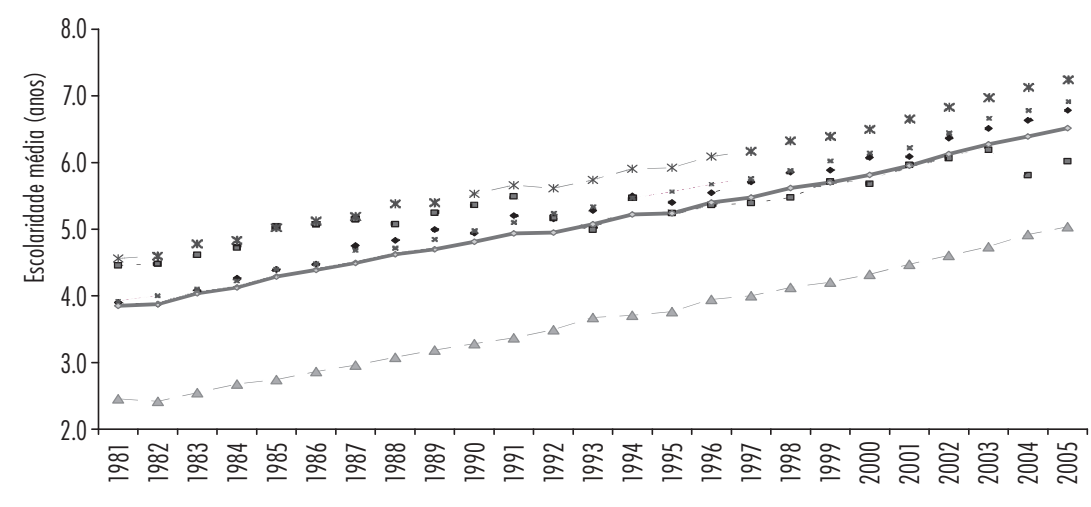

- Regĩ̃o Centro-oeste - - Região Norte $\triangle \Delta$-Região Nordeste $\cdots$ - Região Sul $*$ - Região Sudeste $\backsim$ Brasil

Fonte: Ipeadata, elaborado pelo autor.

Cornia (2004), Barro (2000), Deininger e Squire (1998) e Li, Squire e Zou (1998). Acredita-se que nem a desigualdade nem o déficit educacional desaparecerão nas próximas décadas sem que se adotem políticas orientadas especificamente para melhorar a qualidade e expandir a provisão de educação, principalmente, para os mais pobres.

\section{2 - O Papel das Políticas Públicas}

A educação não possui características de um bem público puro ${ }^{11}$ e seus retornos privados, especialmente no Brasil, são elevados. Apesar disso, existem fundamentos que tornam aceitável e até mesmo desejável a intervenção pública. Eficiência econômica e distribuição de renda justificam tais políticas que podem permitir que os indivíduos, dos mais diferentes níveis de renda, recebam níveis equivalentes de educação.

Em relação ao argumento da eficiência econômica, a presença de externalidades e de imperfeiçóes no mercado de crédito trazem ineficiências que tornam necessária a provisão pública desse bem. A educação consegue produzir externalidades positivas que beneficiam a toda a sociedade. Pode contribuir, por exemplo, para melhor noção de cidadania e menores níveis de criminalidade.

11 Ver Varian (1992). 
Luiz Honorato da Silva Júnior e Yony Sampaio

Outra possível externalidade é observada na presença de trabalhadores mais qualificados, que podem trazer benefícios no ambiente de trabalho facilitando a aprendizagem de seus colegas. O trabalho de Moretti (2004), por exemplo, avaliou a externalidade que existia localmente entre as empresas manufatureiras norte-americanas. Ele mostrou que um aumento de $1 \%$ da proporção dos indivíduos fazendo curso superior numa cidade aumentaria em 0,5\% em média a produtividade dentro das empresas desta cidade (com educação constante dentro da empresa), e o nível de educaçâo médio nas cidades tinha igualmente uma influência sobre os salários individuais.

Além da condição de renda das famílias, outros fatores são relevantes no processo de produção de conhecimento. Sabe-se que há heterogeneidade de habilidades entre os estudantes, alguns conseguem com menor esforço de aprendizagem melhores resultados na vida escolar. Tais diferenças, possivelmente, são uma das causas mais importantes na produção de desigualdades de renda existente. Uma forma alternativa de se suprir a escassez desse fator de produção educacional seria o de encontrar um fator endógeno que apresentasse características de substituição técnica na função de produção educacional. Neste sentido, a qualidade da escola poderia, caso existisse tal característica, suprir a escassez de habilidades.

Por fim, a provisão pública pode garantir igualdade de oportunidades educacionais para crianças de diferentes classes sociais. Além do mais, a educação parece ser um dos principais determinantes da mobilidade social, pois garante melhores oportunidades no mercado de trabalho. ${ }^{12}$

Ao passar dos anos a sociedade brasileira vem elevando a sua percepção acerca da importância da educação e vem através do Estado, incorporando, ao longo de décadas, maiores responsabilidades em relação à educação. A Constituição Brasileira, promulgada em 1988, determina no Artigo 205 que a educaçáo é direito de todos e dever do estado e da família.

Os anos noventa no Brasil foram um marco inicial de algumas importantes leis e políticas educacionais implantadas que evidenciaram maior comprometimento dos governos com a educação. Dentre as mesmas, pode-se citar: a Lei de Diretrizes e Bases da Educação Nacional (LDB); o Fundo de Manutenção e Desenvolvimento do Ensino Fundamental e de Valorização do Magistério (FUndef); o Programa Nacional de Renda Mínima vinculada à educação - "Bolsa Escola"; o Programa para a erradicação do Trabalho Infantil (PETI); os sistemas de avaliação para os diversos níveis de ensino; e, as políticas de cotas e financiamento estudantil. Em seguida será apresentada, de maneira muito, breve a política e seus objetivos. Por serem medidas muito recentes, várias delas ainda náo podem ser examinadas ex post, outras ainda carecem de melhor exame.

A Lei n ${ }^{\circ} 9.394 / 1996$, conhecida como a "nova LDB", talvez tenha sido a mais importante dessas políticas. Entre outros avanços, a nova LDB prevê: a) a extensão do Ensino

12 Ferreira y Veloso (2003) 
Fundamental obrigatório e gratuito para os que não tiveram acesso na idade esperada (entre 7 e 14 anos); b) carga mínima de 800 horas distribuídas em 200 dias na educação básica; c) a formação e qualificação dos docentes; d) a obrigatoriedade de a Uniāo gastar no mínimo $18 \%$ e os estados e municípios no mínimo $25 \%$ de seus respectivos orçamentos na manutençáo e desenvolvimento do ensino público; e) o aumento do ensino fundamental de oito para nove anos, iniciando a obrigatoriedade da escola aos seis anos de idade; e f) a criação do Plano Nacional de Educação (PNE).

Um exemplo de importante política de financiamento à educação, o FUNDEF foi implementado por emenda constitucional em 1996 e determinava que a partir de 1998, $60 \%$ dos recursos destinados a educação fosse para o Ensino Fundamental. A União passou a definir um custo mínimo por aluno e, no caso dos estados e municípios não possuírem recursos suficientes, a União ficaria responsável por complementá-los. A determinação de um mínimo de gasto por aluno era uma sinalização governamental no sentido de diminuir a desigualdade de gastos e consequentemente da qualidade do Ensino Fundamental entre regióes. Outros objetivos do FUNDEF eram: melhorar a remuneração de docentes e outros funcionários envolvidos no Sistema de Educação e, investir na qualificação dos professores.

O Programa Nacional de Renda Mínima vinculada à educação - "Bolsa Escola" foi criado em 2001 pelo governo federal a partir da experiência exitosa do governo do Distrito Federal a partir de 1995. O recebimento da bolsa no valor de R \$15,00 por filho e limitado ao máximo de três, era condicionado à freqüência escolar das crianças cujas famílias não possuíssem renda familiar per capita superior ao fixado em nível nacional que era de $\mathrm{R} \$ 90,00$. Em 2003 o referido programa foi incorporado ao "Programa Bolsa Família", recém criado.

O Programa para a erradicação do Trabalho Infantil (PETI) foi mais um esforço adicional da sociedade brasileira no sentido de tirar as crianças do trabalho infantil. $\mathrm{O}$ Programa oferece uma transferência de renda e exige como contrapartida a freqüência de uma jornada escolar ampliada para as crianças.

Um importante avanço no sentido da melhoria da educação no Brasil foi a criação dos sistemas de avaliaçáo que procuram mensurar o aprendizado dos alunos, e que acompanham as condiçôes de infra-estrutura das escolas e de qualificação dos professores. O Sistema de Avaliação da Educação Básica (SAEB) é aplicado a cada dois anos desde 1995 e produz informaçóes a respeito da realidade educacional nas regióes brasileiras.

Outro instrumento de avaliaçáo é o Exame Nacional do Ensino Médio (ENEM) que se apresenta como uma importante ferramenta de avaliação da qualidade geral do ensino médio no país.

Em 2007 foi criado o Índice de Desenvolvimento da Educação (IDEB). O Ministério da Educaçãao ${ }^{13}$ afirma que o indicador que mede a qualidade da educaçáo foi pensado

\footnotetext{
13 Ver MEC (2009).
} 
Luiz Honorato da Silva Júnior e Yony Sampaio

para facilitar o entendimento de todos, uma vez que o índice é comparável nacionalmente e expressa em valores os resultados mais importantes da educação: aprendizagem e fluxo.

Encontra-se atualmente em discussão formas de aumentar a oferta de vagas no ensino Superior. Neste sentido, o Programa Universidade para Todos (Prouni), instituído em 2005 pelo Governo Federal, tem a proposta de oferecer aos alunos de baixa renda, bolsas de estudo, que podem ser integrais ou parciais, em faculdades privadas. O processo seletivo desses alunos se dá a partir de suas notas no ENEM.

Outro instrumento de financiamento do Ensino Superior ocorre através do Fundo de Financiamento ao Estudante do Ensino Superior (FIES). Trata-se de um programa do Ministério da Educação destinado a financiar a graduação no Ensino Superior de estudantes que não tenham condições de pagamento dos custos de sua formação.

Outro tema de intensa discussão atualmente no país se refere ao Sistema de Cotas, medida que reserva uma fração das vagas nas Universidades públicas para estudantes procedentes de grupos específicos (grupos étnicos ou raciais, classes sociais, deficientes físicos, etc.). A discussão divide opiniôes, entretanto, a única questão que parece consensual é a iminente necessidade de alguma ação pública para diminuição das desigualdades entre os grupos sociais.

Conforme se tentou mostrar aqui, muitas são as açóes no intuito de melhorar a educação no país. A maioria delas é ainda muito recente e seus resultados ex-post ainda precisarão de algum tempo para se revelarem de maneira conclusiva. Mas todo este esforço social recentemente implementado parece evidenciar uma mudança de atitude frente a questão da educação, uma mudança de preferências da sociedade.

\section{CONCLUSÓES}

Com o objetivo de contribuir com uma reflexão acerca da relação entre pobreza e educação no Brasil destacam-se algumas características da pobreza e da distribuição de renda do Brasil e resume-se, o estado atual do sistema educacional brasileiro.

A educação é reconhecida como elemento destacado para mobilidade social. Corroborando, diversas análises têm constatado que a educação explica boa parte das diferenças salariais e de modo geral a desigualdade da renda. Cálculos para o Brasil têm identificado altas taxas de retorno à educação. Por que entáo o nível educacional no Brasil ainda é tão baixo relativamente a países com PIB per capita menor e com economia menos diversificada que a brasileira?

O nível educacional atingido por um indivíduo depende de aspectos relacionados à demanda por educaçáo, a qual se baseia na teoria do capital humano, e à oferta de educaçáo, pelo setor privado ou pelo setor público.

Como determinantes da demanda individual, cinco fatores são decisivos: a renda familiar, as habilidades, o ambiente familiar, a qualidade da escola que ele pretende 
freqüentar e o retorno esperado da educação. Uma interpretação simples destes determinantes destaca uma armadilha de pobreza que tolhe a busca por níveis educacionais mais elevados, mormente quando a oferta de educação é outro fator limitante.

Embora o Brasil tenha atingido universalidade na oferta de ensino fundamental, esta ampliação ocorreu com nível de qualidade muito baixo. Observa-se, por exemplo, grande disparidade entre o sistema educacional público brasileiro que possui características próprias de países em desenvolvimento, e o sistema privado que revela uma realidade completamente diferente, sendo comparável a de países ricos.

De maneira geral, os indicadores educacionais no Brasil são muito ruins, embora venham apresentando significativa melhora em anos recentes. Adicionalmente, a universalização do ensino fundamental vem pressionando o ensino médio, requerendo ampliação do número de escolas e correspondente corpo docente. Esses são desafios que devem ser enfrentados nos próximos anos, mas que dizem respeito fundamentalmente à oferta de ensino.

Mas, e do lado da demanda? Do lado da demanda, há necessidade náo apenas de mostrar a importância da educaçáo como um dos fatores da mobilidade social, destacando seu elevado retorno, o qual, por si deveria se constituir em importante estímulo para ampliar a demanda, mas também enfrentar a armadilha representada pela baixa renda.

O Brasil não é um país necessariamente pobre, e sim, com muitos pobres e com grupo sociais em situação de risco. Famílias com crianças são as mais vulneráveis. Inúmeros estudos têm constatado redução da pobreza de um modo geral, mas há marcantes desigualdades regionais. Há grande concentração dos pobres no Norte e no Nordeste, onde coincidentemente os níveis educacionais são mais baixos. Programas como o Bolsa Família e o PETI tem destino explícito de estimular a manutenção das crianças na escola e desestimular o ingresso precoce no mercado de trabalho, determinado seja por miopia, em estimar fluxos futuros de renda decorrentes de uma maior educação ou por problemas de liquidez que requeiram um aporte de contribuição dos filhos, principalmente quando a renda e o nível de educação dos pais são muito baixos. Mas estes programas só serão mais efetivos se houver monitoramento das condicionalidades e as condiçóes de saída foram bem especificadas, o que não parece ser o caso. Mas não se pode descuidar, igualmente das condiçóes de oferta, salientando-se a qualidade do ensino oferecido.

Em anos recentes a sociedade brasileira vem elevando a sua percepção acerca da importância da educação como estabelecido em sua carta magna: educação é direito de todos e dever do estado e da família. Tal mudança tem sido combustível para implementação de políticas transformadoras como FUNDEF, Bolsa Escola, Peti, os sistemas de avaliação para os diversos níveis de ensino e as políticas de cotas e financiamento estudantil. Contudo, observa-se que os desafios no sentido da melhoria da qualidade do sistema educacional público que estão postos diante da sociedade são de grande magnitude. 
Luiz Honorato da Silva Júnior e Yony Sampaio

\section{REFERÂNCIAS}

Atkinson, A. B. Is rising income inequality inevitable? A critique of the transatlantic consensus. WIDER Annual Lecture no. 3, 1999.

Amadeo, Edward et al., "A natureza e o funcionamento do mercado de trabalho desde 1994”, Texto para discussáo núm. 353, Rio de Janeiro, Ipea, mimeo 1994.

Arbache, Jorge Saba, "Pobreza e mercados no Brasil." en Pobreza e Mercados no Brasil: uma análise de iniciativas de políticas públicas, Brasília, CEPAL: escritório no Brasil \& Department for International Development, 2003.

Baer, Werner, A economia brasileira, São Paulo, Nobel, 2002.

Barham, Vicky, et al., "Education and the poverty trap", en European Economic Review, Elsevier, vol. 39(7), 1995, pp. 1257-1275.

Barro, R. Inequality and growth in a panel of countries. Journal of Economic Growth 5, 5-32, 2000.

Barros, Alexandre Rands, "Desigualdades regionais no Brasil: causas da reversão da tendência na última década”, en Texto para discussão núm. 404, Recife, PIMES, 1997.

Barros, Ricardo Paes, et al., "A desigualdade da pobreza: estratégias ocupacionais e diferenciais por gênero" en Texto para discussão n 453, Rio de Janeiro, IPEA, 1997.

, et al., "A estabilidade inaceitável: desigualdade e pobreza no Brasil", Texto para discussão no 800, Rio de Janeiro , IPEA, 2003.

Barros, Ricardo P. et al., A desigualdade da pobreza: estratégias ocupacionais e diferenciais por gênero. Texto para discussáo no 453, Rio de Janeiro, IPEA, 1997.

Brunello, Giorgio y Danielle Checchi. School quality and family background in Italy. Economics of Education Review 24, 563-577, 2005.

Carneiro, Francisco Galrão, "Perfil da pobreza e aspectos funcionais dos mercados de trabalho no Brasil", en Pobreza e mercados no Brasil, Brasília, CEPAL, 2003.

Checchi, Daniele, The economics of education: human capital, family background and Inequality, Cambridge, Cambridge University Press, 2007.

Cornia, G. A. Inequality, growth and poverty in an era of liberalization and globalization. Oxford: Oxford University Press, 2004.

Deininger, K. e L. Squire. New ways of looking at old issues: inequality and growth. Journal of Development Economics 57, 259-287, 1998. Ferreira, Sergio Guimarães y Veloso, Fernando. Mobilidade intergeracional de educação no Brasil. Encontro nacional da ANPEC, 2003. Disponivel em http://www.anpec.org.br/encontro2003/artigos/F25.pdf

, "A reforma da educaçâo", en Rompendo o marasmo: a retomada do desenvolvimento no Brasil, Rio de Janeiro, Elsevier, 2006.

Gurgand, Marc, Économie de l'éducation, Paris, Édition La Découverte, 2005.

Hoffmann, Rodolfo, Distribuição de renda: medidas de desigualdade e pobreza, Sáo Paulo, USP, 1998. 
IBGE - Instituto Brasileiro de Geografia e Estatística, Microdados da Pesquisa Nacional por Amostra de Domicílios (PNAD), 2007.

IDEB - Índice de Desenvolvimento da Educação Básica, Resultados e metas, Disponível em http://ideb.inep.gov.br/site/. Último acesso em 8 de dezembro de 2009.

INEP - Instituto Nacional de Estudos e Pesquisas Educacionais Anísio Teixeira, Dados Estatísticos: Números da Educação no Brasil, http://www.inep.gov.br, vários acessos, 2009.

Lange, Fabian y Robert Topel, "The social value of education and human capital", en Handbook of the Economics of Education, vol. I, edited by Eric A. Hanushek and Finis Welch, 2006.

Lee, Jong-Wha e Robert Barro, "Schooling quality in a cross-section of countries." Economica 68, 2001, pp. 465-488.

Li, H., L. Squire e H. Zou. Explaining international and intertemporal variations in income inequality. Economic Journal, 108, 26-43, 1998.

MEC - Ministério da Educação, Índice de desenvolvimento da educação básica, http://www.portal.mec.gov.br. Vários acessos, 2009.

Menezes-Filho, Naércio. "Educação e desiguladade", en Microeconomia e Sociedade, Marcos de Barros Lisboa e Naércio Aquino Menezes-Filho, Rio de Janeiro, FGV, 2001.

Moretti, Enrico, "Workers education, spillovers and productivity: evidence from plantlevel production functions." American Economic Review, vol. 94, 2004, pp. 656-690.

OCDE, PISA 2006: competências em ciências para o mundo de amanhä (volumes 1 e 2). Disponível em http://www.pisa.oecd.org, 2008.

Rocha, Sônia Maria Rodrigues, Pobreza no Brasil: afinal do que se trata?, Rio de Janeiro, editora FGV, 2005.

Sabóia, João e Sonia Rocha. An Evaluation Methodology for Minimum Income Programmes in Brazil, Genebra, The International Labour Office, 2002.

Silva Júnior, Luiz Honorato da, Pobreza na população rural nordestina: uma análise de suas caracteristicas durante os anos noventa, Rio de Janeiro, BNDES, 2006.

, Pobreza, qualidade da escola e background familiar influenciando a educação no brasil: Uma análise à luz da teoria do capital humano, Tese de Doutorado, Recife, PIMES, 2009.

Varian, Hal, Microeconomic Analisys, New York, IE-www Norton, 1992.

World Bank, The. "Development data \& statistics", New York, 2005. 
